\title{
CONTEXTUALIZAÇÃO NO ENSINO DO EQUILÍBRIO QUÍMICO: UMA PROPOSTA METODOLÓGICA
}

\author{
Pedro Hermano Menezes de Vasconcelos ${ }^{1}$, Alexandre Fábio e Silva de Araújo ${ }^{1}$, \\ Wladiana Oliveira Matoss ${ }^{2}$ \\ ${ }^{1}$ Instituto Federal de Educação, Ciência e Tecnologia do Ceará - IFCE \\ Programa de Pós-graduação em Ensino de Ciências e Matemática (PPGECM) \\ ${ }^{2}$ Universidade Federal do Ceará - UFC \\ <pedro_hermano@yahoo.com.br>, <afsa_quimica@yahoo.com.br> \\ <wladianamatos@ufc.br>
}

DOI: 10.21439/conexoes.conexoes.v10i4.979

\begin{abstract}
Resumo. A proposta deste trabalho foi mostrar que a contextualização constitui uma ferramenta metodológica importante para o desenvolvimento de conceitos no processo de ensino e pode ser bem aplicada ao tema Equilíbrio Químico, a partir de reações que façam parte do cotidiano dos alunos. Foi realizado um estudo de caráter descritivo, exploratório com abordagem qualitativa. Com o uso de exemplos do cotidiano durante a prática docente, pode-se perceber a importância da contextualização no ensino de química, pois a aula contextualizada tornou-se uma estratégia que contribuiu para a motivação e interesse dos alunos pela disciplina. Os resultados evidenciam que quando um determinado assunto é desenvolvido utilizando-se da contextualização e da interdisciplinaridade além de um maior interesse há um melhor desenvolvimento por parte dos alunos. Portanto a aula contextualizada se apresenta com uma estratégia essencial para o processo ensino/aprendizagem, pois como é amplamente conhecido no processo da educação em ciências, as tradicionais estratégias de ensino, como o quadro e pincel, não são suficientes para assegurar que os alunos realmente assimilem os conceitos científicos. Assim, pode-se concluir que a contextualização é uma ferramenta que contribui significativamente para o processo de ensino/aprendizagem.
\end{abstract}

Palavras-chaves: Contextualização, Ensino, Equilíbrio Químico.

Abstract. This article has the purpose to show the experience of contextualization is an important methodological tool for the development of concepts in the teaching process and can be applied successfully to the topic Chemical Equilibrium, considering reactions that are part of students' daily lives. This was a descriptive, exploratory study with a qualitative approach. With the use of everyday examples for teaching practice, it was verified the importance of context in chemistry teaching, since the contextualized class became a strategy that contributed to the motivation and interest of students by discipline. The results showed that when a particular subject is developed using the contextualization and interdisciplinary as well as a greater interest there is a better development by students. So the contextual lesson is presented with an essential strategy for the teaching/learning process, because as it is known in the science education process, traditional teaching strategies such as blackboard and brush are not enough to ensure that students really learn scientific concepts. The work leads to the conclusion that contextualization is a methodology that contributes significantly to the teaching/learning process.

Keywords: Contextualization. Teaching. Chemical Equilibrium.

\section{INTRODUÇÃO}

A disciplina de Química está inserida como componente curricular dos ensinos fundamental e médio. $\mathrm{O}$ ensino desta matéria deve ser transmitido de tal forma que os alunos tenham a possibilidade de compreender as mudanças ocorrem no mundo que os cerca, de uma forma mais extensa e integrada, para que estes possam 
analisar, com maior fundamentação, as informações adquiridas nos mais diversos meios de comunicação (a mídia, a escola, as pessoas, etc) (BRASIL, 1999a).

A metodologia tradicionalista de ensino afirma que "para ensinar basta saber um pouco do conteúdo específico e utilizar algumas técnicas pedagógicas, já que a função do ensino é transmitir conhecimentos que deverão ser retidos pelos alunos" (SCHNETZLER, 2002). Porém não contextualizar a Química pode levar os alunos a desenvolverem um alto nível de rejeição pelo estudo desta ciência, tornando cada vez mais difícil seu processo de ensino-aprendizagem. Fechando um ciclo pernicioso causado pela formação ineficiente dos professores que não são preparados para a contextualização dos conteúdos (NARCISO JR.; JORDÃO, 2005). A contextualização do ensino, por outro lado, não dificulta a resolução de questões tradicionais de química, sobretudo se elas forem desenvolvidas com o objetivo de avaliar não a evocação de fatos, fórmulas ou dados, porém sim as competências e habilidades para se trabalhar o conhecimento (CHASSOT, 1995).

A prática da contextualização durante o processo de ensino-aprendizagem objetiva levar o cotidiano para o ambiente escolar, concomitantemente busca vincular o dia-a-dia dos alunos ao conhecimento científico (MALDANER; ZANON, 2007); abordagens como essas, em matérias que exigem do aluno o exercício da abstração como a química (SCHNETZLER; SANTOS, 2003), são extremamente importantes.

Levando-se em conta especificamente o ensino do Equilíbrio Químico, constata-se que as práticas pedagógicas, muitas vezes, têm como base aulas expositivas, que não levam em consideração os conhecimentos prévios e o dia-a-dia dos alunos (GARRITZ; RAVIOLO, 2008). Isto torna o ensino deste assunto desinteressante e o que é dito pelo professor em sala é tomado com "verdade absoluta".

A proposta central deste trabalho foi mostrar que a contextualização pode constituir uma ferramenta metodológica essencial para a construção de conceitos no processo de ensino e pode ser bem aplicado ao tema Equilíbrio Químico, a partir de reações que façam parte do cotidiano dos alunos. Especificamente, foram pesquisados e selecionados exemplos de Equilíbrio Químico no cotidiano para usá-los na contextualização do assunto e verificou-se se o uso da contextualização tornou o assunto mais didático e contribuiu para melhorar o processo de ensino e aprendizagem.

\section{FUNDAMENTAÇÃO TEÓRICA \\ 2.1 A PESQUISA NO ENSINO DE QUÍMICA}

Para dar o conceito à pesquisa em ensino de Química, tem-se a necessidade de, antes, discutir como a relação pesquisa e ensino vem sendo articulada nessas últimas 4 décadas que marcam a origem e a evolução desta nova área. Isto porque a educação química tem outro objeto de estudo e de investigação, conforme exposto, no primeiro trabalho sobre pesquisa em ensino de Química lançado na revista Química Nova na Escola:

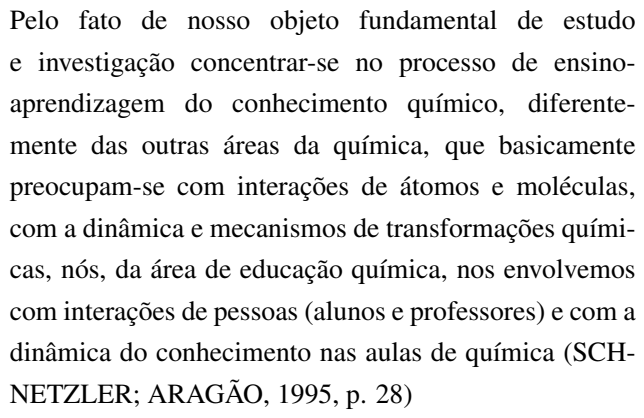

Isso nos evidencia que a posse do conhecimento químico é fator preponderante para a elaboração de análises na área de ensino, entretanto não é suficiente, devido à complexidade de seu objeto e das inter-relações humanas e sociais que o caracterizam. Por tal motivo, se faz necessário recorrer a contribuições teóricas das mais variadas Ciências Humanas, não se tratando de simples aplicação das mesmas à área da educação química (??).

Isto posto, entendemos que a identidade deste novo campo de investigação é marcado pela especificação do conhecimento científico, que se encontra no cerne dos processos de ensino e de aprendizagem estudados, levando a investigações acerca de metodologias mais adequadas ao ensino do conteúdo trabalhado e pesquisas referentes a métodos de reelaboração de conceitos para o ensino de determinado conhecimento em contextos escolares determinados (TURCI et al., 2016). Isso nos diz que o ensino de química reflete a reformulação do conhecimento químico em conhecimento escolar, o que implica a necessidade da criação de uma nova área de estudo e investigação, em que questões relevantes sobre o que, como e porque ensinar química constitui a raiz das pesquisas (SCHNETZLER, 2002).

\subsection{A CONTEXTUALIZAÇÃO DOS CONTEÚDOS}

A prática da contextualização surgiu com a reelaboração curricular do ensino médio, em conformidade a Lei de Diretrizes e Bases da Educação (LDB-9.394/97) 
que orienta a compreensão dos conhecimentos científicos para uso no cotidiano. Teve origem nas diretrizes que são determinadas pelos Parâmetros Curriculares Nacionais $(\mathrm{PCN})$, que visam um processo de ensino e aprendizagem da química centrado no elo entre o conceito científico e social. Contextualizar a química não seria apenas formar uma ligação artificial entre o conhecimento e o dia a dia do aluno, não é apenas utilizar exemplos como ilustração ao fim de um assunto, mais que isso, contextualizar é mostrar situações reais e buscar o conhecimento químico/científico necessário para compreendê-las (WARTHA; SILVA; BEJARANO 2013).

Em tempos atuais as metodologias aplicadas ao ensino de química têm sido direcionadas por uma grande tendência à contextualização dos assuntos abordados em sala, suplementando os currículos com questões sociais, políticas, econômicas, ambientais, éticas, morais e culturais relevantes ou meio científico e tecnológico. (PONTES, 2008).

De acordo com a LDB, o processo de ensino e aprendizagem de química deve contribuir na educação de modo a ajudar no desenvolvimento e construção do conhecimento científico do discente, inserindo-o na sociedade e não o deixando a margem da mesma. A metodologia de ensino que emprega a contextualização dos temas abordados em sala de aula traz maior significado aos conceitos que estão sendo aprendidos. Os PCNEM nos dizem que o processo de aprendizagem ocorre em fases, em que na primeira se dá a mudança conceitual do aluno, para depois ocorrer a fase da contextualização. Segundo esse documento, a mudança conceitual acontece devido ao confronto entre as ideias do senso comum e as do conhecimento científico.

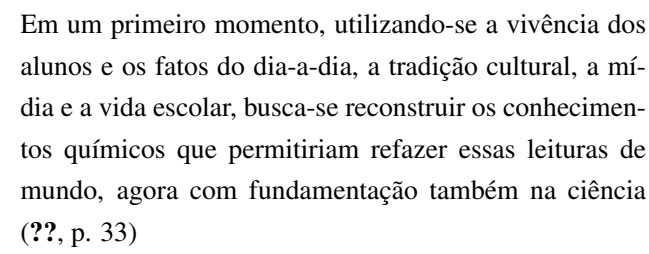

Porém, é no momento da mudança conceitual do estudante que se dá a necessidade de se levar em consideração os aspectos macro e microscópicos, as explicações e a linguagem científica na construção do conhecimento, ou seja:

\footnotetext{
“(...) é importante apresentar ao aluno fatos concretos, observáveis e mensuráveis, uma vez que os conceitos que o aluno traz para a sala de aula advêm principalmente de sua leitura do mundo macroscópico" (??, p. 33)
}

Além do supracitado, leva-se em consideração que para um conhecimento abrangente e de qualidade, é necessário que sejam abordados em sala de aula e estudados pelos alunos os modelos explicativos microscópicos. Desta forma, a contextualização dos conteúdos aproxima o estudo da química ao cotidiano dos alunos, além de facilitar o processo de ensino e aprendizagem de conteúdos considerados mais difíceis, levando a uma maior motivação para se aprender fenômenos químicos que até o momento encontravam-se distantes do senso comum (BEJARANO; CARVALHO, 2000).

\subsection{FUNÇÃO SOCIAL DO ENSINO DE QUÍMICA}

Conforme dispõe a Constituição Brasileira e a legislação de ensino, a educação voltada para a cidadania é função de alta relevância. Outrossim, tal função tem sido bastante difundida pelos professores do ensino médio, o qual inclui o ensino de química. O ensino desta disciplina deve orientado no afã de desenvolver a capacidade de tomada de decisão, o que propicia a necessidade de vincular o conteúdo visto em sala de aula com o contexto social em que o aluno vive (TAROCO. 2015). Podemos destacar que os pontos negativos relacionados às práticas pedagógicas utilizadas no atual ensino de química englobam desde a postura pouco participativa dos alunos em sala até os métodos de avaliação (SANTOS et al., 2013).

Nas palavras de Cardoso e Colinvaux:

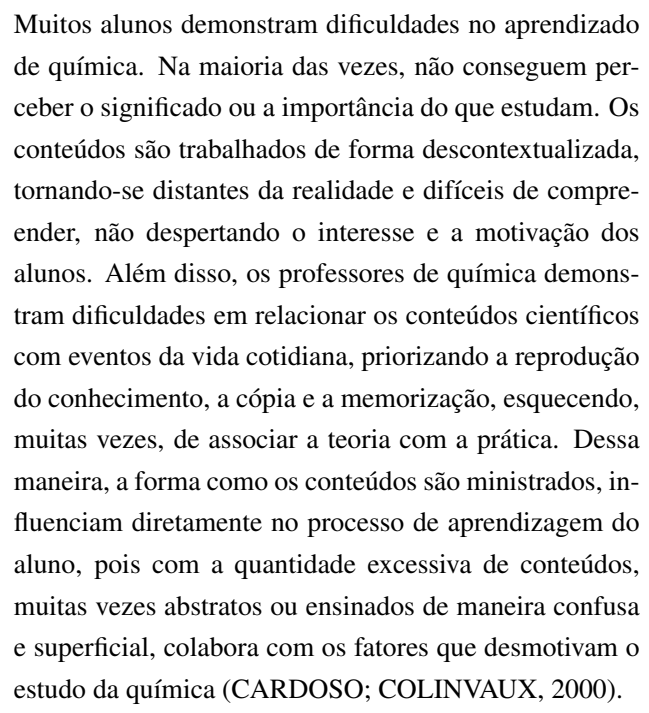

Em contrapartida, ideias mais progressistas refletem a possibilidade de se chegar a produção do conhecimento e a formação continuada de um cidadão crítico, em condições de analisar, entender e usar este conhecimento em seu dia a dia, tendo respaldo para perceber e 
interferir em situações que contribuam para a melhoria de sua qualidade de vida. Nessa concepção, é interrelacionando-se com o mundo que o aluno pode medrar seus primeiros conhecimentos científicos através de atividades presentes no seu dia a dia (MOREIRA; MASINI, 2006).

\section{METODOLOGIA}

\subsection{TIPO DE ESTUDO}

Tratou-se de um estudo descritivo, exploratório com abordagem qualitativa. A opção por um trabalho de caráter descritivo encontrou apoio em Vergara (2000), no tocante em que defende o fato da pesquisa descritiva expor as características de uma determinada população ou fenômeno, estabelecendo correlações entre variáveis e definindo sua natureza sem o compromisso de explicar os fenômenos que descreve, embora sirva de base para tal explicação. Pesquisas exploratórias são aquelas que envolvem levantamento bibliográfico, aplicação de questionário, análise de exemplos que estimulam a compreensão ou ainda entrevistas com indivíduos que detenham conhecimento prático relacionado ao problema pesquisado (GIL, 2010).

\subsection{LOCUS DA PESQUISA E SEU PÚBLICO ALVO}

A pesquisa foi realizada em Fortaleza no Colégio da Polícia Militar do Ceará General Edgard Facó, escola da rede pública de ensino do estado. O trabalho foi desenvolvido com os estudantes do $2^{\circ}$ ano do Ensino Médio durante o segundo semestre de 2014, visto que o tema Equilíbrio Químico é incluído nesse período nos conteúdos ministrados nesta série. Aplicou-se o estudo em 03 turmas do turno da manhã e 01 turma do turno da tarde, totalizando 126 alunos.

\subsection{TÓPICOS REFERENTES AO EQUILÍBRIO QUÍ- MICO}

Os tópicos sobre equilíbrio químico abordados nas turmas nas quais este trabalho foi desenvolvido seguem abaixo:

a) Equilíbrios químicos homogêneos (04 aulas)

- Grau de equilíbrio

- Constante de equilíbrio

- Deslocamento do equilíbrio

b) Equilíbrios iônicos em soluções aquosas (04 aulas)

- Equilíbrios iônicos

- Equilíbrio iônico na água/pH e pOH
- Solução-tampão

c) Equilíbrios heterogêneos (04 aulas)

- Lei da ação das massas

- Deslocamento do equilíbrio heterogêneo

- Produto de solubilidade (KPS)

\section{METODOLOGIA AVALIATIVA}

O desenvolvimento da aprendizagem foi analisado periodicamente por meio de avaliações e dinâmicas de grupo elaboradas pelo professor. Essa metodologia tem fundamentação no princípio de que é possível para o docente saber o que seus alunos estão aprendendo enfatizando a contextualização, a interdisciplinaridade e a reprodução e abstração do conteúdo através das atividades desenvolvidas em sala. Desde o início, o currículo escolar privilegia o preparo para o vestibular e o ENEM e apresenta uma postura bastante rígida em relação à disciplina.

Foram realizadas buscas bibliográficas de aplicações de Equilíbrio Químico no cotidiano em artigos e revistas sobre educação em química e em livros que abordam o assunto Equilíbrio Químico para serem utilizadas nas aulas que seriam ministradas.

Ao final do desenvolvimento da metodologia um questionário foi aplicado aos alunos, contendo as quatro questões abaixo.

1. Para você, a contextualização do equilíbrio químico ajudou a compreender mais facilmente esse assunto?

2. A contextualização do equilíbrio químico despertou em você maior interesse pela aula?

3. A contextualização do equilíbrio químico te ajudou a perceber a importância desse assunto na vida cotidiana?

4. Você gostaria que as aulas das outras matérias também fossem ensinadas abordando a contextualização dos tópicos abordados?

\section{A CONTEXTUALIZAÇÃO DO EQUILÍBRIO QUÍMICO}

\subsection{EQUILÍBRIO QUÍMICO NO COTIDIANO}

Após pesquisas, os exemplos de Equilíbrio Químico no cotidiano selecionados na literatura e utilizados na contextualização das aulas deste trabalho, foram: 


\subsubsection{O Equilíbrio Químico na respiração celular}

Texto extraído do livro Físico-Química do autor Ricardo Feltre (FELTRE, 2004). O oxigênio do ar que respiramos, ao chegar aos pulmões, entra em contato com a hemoglobina (Hem) do sangue, dando origem à oxihemoglobina $\left(\mathrm{HemO}_{2}\right)$, substância responsável pelo transporte de $\mathrm{O} 2$ até as células de todo o organismo. Assim, ocorre no sangue o seguinte equilíbrio:

$$
\mathrm{Hem}_{(a q)}+\mathrm{O}_{2} \rightleftharpoons \mathrm{HemO}_{2(a q)}
$$

Sempre que alguém se desloca para locais de altitude mais elevada, a quantidade de $\mathrm{O}_{2}$ no sangue diminui, causando o deslocamento do equilíbrio para a esquerda (lado dos reagentes), como previsto no princípio de Le Chatelier. Com isso, reduz-se a quantidade de oxihemoglobina, comprometendo a chegada de $\mathrm{O}_{2}$ às células de todo o organismo; a pessoa sente fadiga e tontura, e pode até morrer em casos extremos (FELTRE, 2004).

\subsubsection{Equilíbrio Químico de sais pouco solúveis}

Texto extraído do artigo Equilíbrio Químico de Sais Pouco Solúveis e o Caso Celobar (SENE et al., 2006).

Durante o ano de 2003, um evento que envolveu a morte de ao menos 23 pessoas despertou a atenção da opinião pública. Pesquisas realizadas na época apon-

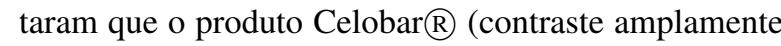
usado em exames radiológicos) teve a composição alterada no decorrer de sua produção.

A tragédia ocorreu devido a troca, nas soluções de contrastes, de sulfato de bário $\left(\mathrm{BaSO}_{4}\right)$ por carbonato de bário $\left(\mathrm{BaCO}_{3}\right)$. O cátion $\mathrm{Ba}^{2+}$ é bastante tóxico, entretanto o $\mathrm{BaSO}_{4}$ pode ser ingerido por pacientes para servir como contraste nas radiografias. Sua ingestão não representa risco algum, devido a esse sal ser extremamente insolúvel.

$$
\mathrm{BaSO}_{4(s)} \rightleftharpoons \mathrm{Ba}_{(a q)}^{2+}+S O_{4(a q)}^{2-} \mathrm{KPS}=1.10^{-10}
$$

Já o $\mathrm{BaCO}_{3}$, por ser um pouco mais solúvel (em água apresenta: solubilidade $=0,024 \mathrm{~g} \cdot \mathrm{dcm}^{-3}$ e Kps = 8.10-9) libera uma maior quantidade $\mathrm{de} \mathrm{Ba}^{2+}$, sendo usado inclusive como veneno para ratos. (SENE et al. 2006).

$$
\mathrm{BaCO}_{3(s)} \rightleftharpoons \mathrm{Ba}_{(a q)}^{2+}+\mathrm{CO}_{3(a q)}^{2-} \mathrm{KPS}=8.10^{-9}
$$

\subsubsection{Equilíbrio Químico no consumo de refrige- rantes}

Texto extraído do livro Química - Meio ambiente, Cidadania e Tecnologia da autora Martha Reis (REIS. 2012).

Nas bebidas refrigerantes ocorre a formação do equilíbrio químico:

$$
\mathrm{H}_{2} \mathrm{O}_{\mathrm{l}}+\mathrm{CO}_{2} \rightleftharpoons \mathrm{H}_{2} \mathrm{CO}_{3(a q)} \rightleftharpoons \mathrm{HCO}_{3(a q)}^{-}+\mathrm{H}_{(a q)}^{+}
$$

Quando se ingere um refrigerante, três fatores contribuem para que o equilíbrio seja deslocado no sentido da liberação do gás carbônico, provocando então a chamada eructação (arroto):

1. Presença do ácido no estômago: aumentando a concentração de produtos da reação causa o deslocamento do equilíbrio no sentido dos reagentes, liberando $\mathrm{CO}_{2}(\mathrm{~g})$.

2. Diminuição da pressão: o $\mathrm{CO}_{2}(g)$ é engarrafado nos refrigerantes sob alta pressão e, quando o recipiente que é aberto e a bebida é ingerida, a pressão diminui. A diminuição da pressão desloca o equilíbrio para o lado de maior volume, portanto ter-se-á o escape do $\mathrm{CO}_{2}(g)$.

3. Aumento da temperatura: a solubilidade do $\mathrm{CO}_{2}(g)$ em água diminui conforme a temperatura aumenta. No refrigerante gelado o $\mathrm{CO}_{2}(g)$ apresenta uma solubilidade bem maior que a $37^{\circ} \mathrm{C}$ (temperatura média do organismo) o que provoca a liberação do $\mathrm{CO}_{2}(g)$ quando consumimos a bebida (REIS, 2012).

\subsubsection{Equilíbrio Químico nos dentes}

Texto extraído do artigo A Química e a Conservação dos Dentes (SILVA et al., 2001).

A hidroxiapatita, $\mathrm{Ca}_{5} \mathrm{OH}\left(\mathrm{PO}_{4}\right)_{3(s)}$ é o constituinte fundamental do esmalte dos dentes. Por estar em meio aquoso (saliva) a hidroxiapatita entra em equilíbrio de dissociação de seus íons:

$$
\mathrm{Ca}_{5} \mathrm{OH}\left(\mathrm{PO}_{4}\right)_{3(s)} \rightleftharpoons 5 \mathrm{Ca}_{(a q)}^{2+}+\mathrm{OH}^{-}+3 \mathrm{PO}_{4 \underset{(\mathrm{aq})}{3-}}^{3-}
$$

À medida que a placa bacteriana cresce, a concentração dos ácidos orgânicos produzidos pelas bactérias cresce, aumentando a concentração dos íons $\mathrm{H}_{3} \mathrm{O}^{+}$, segundo a equação (SILVA et al. 2001):

$$
R-\mathrm{COOOH}_{(a q)}+\mathrm{H}_{2} \mathrm{O}(\mathrm{l}) \rightarrow \mathrm{H}_{3} \mathrm{O}_{(a q)}^{+}+\mathrm{R}-\mathrm{COO}_{(a q)}^{-}
$$


Os íons $\mathrm{H}_{3} \mathrm{O}^{+}$reagem com os íons $\mathrm{OH}_{-}$, produzidos na desmineralização, levando à formação de água:

$$
\mathrm{H}_{3} \mathrm{O}_{(a q)}^{+}+\mathrm{OH}_{(a q)}^{-} \rightarrow 2 \mathrm{H}_{2} \mathrm{O}_{(l)}
$$

$\mathrm{O}$ consumo dos ânions $\mathrm{OH}_{-}$ocasiona o deslocamento do equilíbrio da Reação 5 no sentindo direto, causando a desmineralização. O resultado é uma perda de material do dente.

A diminuição do $\mathrm{pH}$ na boca pode ser causada diretamente pelo consumo de frutas ácidas e bebidas, ou indiretamente pela ingestão de alimentos contendo carboidratos fermentáveis que permitem produção de ácidos pelas bactérias (SILVA et al. 2001).

\section{RESULTADOS E DISCUSSÃO}

O mesmo conteúdo foi trabalhado nas seis turmas. Entretanto, aplicou-se a metodologia apenas em quatro turmas. Nas turmas 1 e 4 havia 32 alunos em cada, já nas turmas 2 e 3 havia 31 alunos em cada. Nas turmas 5 e 6, nas quais não foi aplicada a metodologia, havia 32 alunos em cada.

A mesma prova, contendo 8 questões, foi aplicada para todas as turmas. A Tabela 1 apresenta os dados estatísticos das notas obtidas pelos alunos das seis turmas. A Figura 1 apresenta a frequência das notas obtidas por todos os estudantes.

Tabela 1: Dados estatísticos das notas obtidas pelos alunos de cada turma.

\begin{tabular}{|l|l|l|l|}
\hline Turma & Aplic. Metodol. & Média & Desvio-padrão \\
\hline Turma 1 & Sim & 8,90 & 1,12 \\
\hline Turma 2 & Sim & 9,15 & 0,73 \\
\hline Turma 3 & Sim & 9,29 & 0,89 \\
\hline Turma 4 & Sim & 9,35 & 0,85 \\
\hline Turma 5 & Não & 6,58 & 1,87 \\
\hline Turma 6 & Não & 5,67 & 2,02 \\
\hline
\end{tabular}

Analisando a Tabela e o Gráfico 1] percebe-se um considerável aumento das médias dos alunos nas turmas em que foi aplicada a metodologia. Além de melhores médias, as turmas apresentaram notas com mais uniformidade, visto que o desvio padrão diminuiu.

A Tabela 2 apresenta os dados estatísticos relativos ao total de alunos em que foi aplicada a metodologia e com o total de alunos em que a metodologia não foi aplicada.

Os dados da Tabela 2 evidenciam que a aplicação da metodologia utilizada é bastante promissora. $\mathrm{O}$ au-

\footnotetext{
${ }^{1} \mathrm{O}$ desvio padrão $\sigma$ é a medida mais usual para uma dispersão estatística. Ele nos diz o quanto de variação ou dispersão há em uma média ou valor esperado (CORREA. 2003).
}

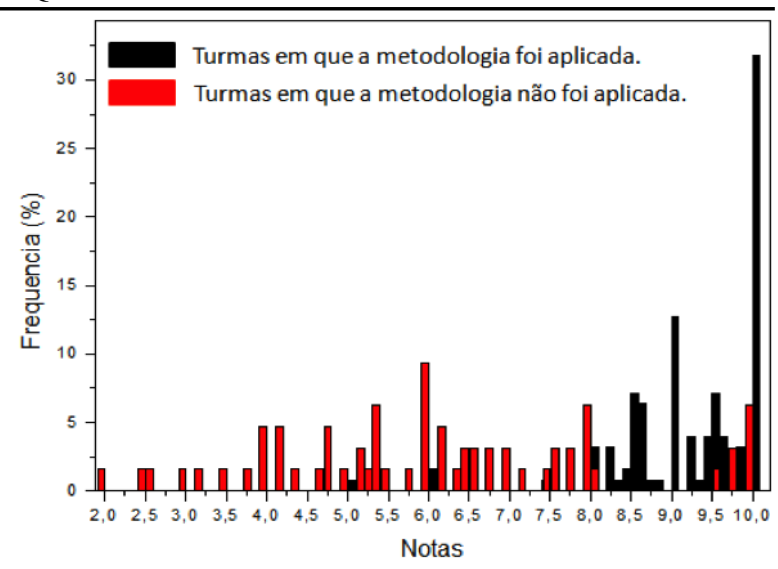

Figura 1: Histograma referente às notas obtidas pelos estudantes.

Tabela 2: Dados estatísticos das notas obtidas pelo total de alunos.

\begin{tabular}{|l|l|l|}
\hline Aplic. da Metodologia & Média & Desvio-padrão \\
\hline Sim & 9,17 & 0,92 \\
\hline Não & 6,12 & 1,98 \\
\hline Diferença (\%) & 49,80 & $-53,74$ \\
\hline
\end{tabular}

mento de 49,80 \% nas notas dos alunos revela um melhor rendimento da aprendizagem, já a diminuição de $53,74 \%$ no desvio padrão indica que a dispersão das notas foi consideravelmente minimizada, sugerindo que a metodologia teve êxito quanto a despertar o interesse dos discentes pelo conteúdo. Com o uso desta metodologia durante a prática docente pode-se perceber que é de grande importância a contextualização no ensino de química, pois a aula contextualizada tornou-se uma estratégia que contribuiu para a motivação e interesse dos alunos pela disciplina. Sabe-se que o processo de ensino/aprendizagem é complexo, sofre mudanças no decorrer tempo, envolve múltiplos saberes e está distante de ser trivial (MOL, 2012). Por tal motivo deve-se ter a consciência de que o ensino de química deve ser trabalhado com o intuito de despertar o interesse por temas cada vez mais ligados ao cotidiano dos alunos. A aula contextualizada foi uma estratégia que contribuiu para a motivação no processo ensino/aprendizagem, pois como é amplamente conhecido no processo da educação em ciências, as tradicionais estratégias de ensino como o quadro e giz/pincel, não são suficientes para assegurar que os alunos, realmente assimilem os conceitos científicos (ASTOLFI; DEVELAY, 2014). 


\subsection{AVALIAÇÃO DO QUESTIONÁRIO APLICADO}

Através das respostas dos alunos ao questionário, infere-se que os mesmos têm melhor clareza do significado de equilíbrio químico e maior facilidade para representar adequadamente exemplos quando existe uma contextualização do assunto, visto que todos os discentes responderam que a contextualização do equilíbrio químico ajudou a compreender mais facilmente o conteúdo (Questão 01).

Dos 126 alunos, apenas 3 relataram que não tiverem seu interesse pela aula despertado com a contextualização (Questão 02), e todos concordaram que a contextualização auxilia a percepção da importância do conteúdo (Questão 03).

No tocante ao processo de ensino e aprendizagem as respostas deixam claro que os discentes gostariam que suas aulas fossem mais contextualizadas e que trouxessem para a sala de aula fatos correlacionados com seu dia a dia, visto que cem por cento dos alunos responderam afirmativamente a Questão 04.

A estes resultados, corrobora-se a percepção que se pode obter na vivência em sala de aula. Em momentos anteriores ao da aplicação deste método em sala fazia-se notório o afastamento por parte dos alunos em relação aos assuntos abordados durante as aulas, fato que, praticamente, não foi observado durante o desenvolvimento desta metodologia, evidenciando que não contextualizar a ciência como um todo pode gerar um alto nível de rejeição desse tipo de estudo por parte dos alunos, dificultando o processo de ensino-aprendizagem.

Após o término de cada tópico abordado uma lista de exercícios com questões de vestibulares e do Enem foi entregue aos alunos e os mesmos afirmavam não ter dificuldade em resolvê-las, o que nos mostra que usar esta ferramenta de ensino não torna o aluno incapaz de resolver questões tradicionais, principalmente se elas forem elaboradas com o intuito de avaliar, não as fórmulas, equações e/ou dados, porém sim a capacidade de abstração do conhecimento.

\section{CONSIDERAÇÕES FINAIS}

Durante o período em que esta metodologia foi desenvolvida observou-se que realmente os alunos conseguem entender melhor o tópico abordado quando o mesmo possui alguma relação com sua vida cotidiana. Os resultados evidenciaram que quando um determinado assunto é desenvolvido utilizando-se da contextualização e da interdisciplinaridade há um maior interesse e melhor desenvolvimento por parte dos alunos. Através das respostas dos discentes ao questionário, inferiu-se que os mesmos passaram a ter melhor clareza do significado de equilíbrio químico e maior facilidade para representar adequadamente os exemplos quando existe uma contextualização do assunto. O contexto mais próximo e mais facilmente explorável para dar sentido aos tópicos do processo de aprendizagem é o do dia a dia e o da convivência pessoal. No que diz respeito ao processo de ensino/aprendizagem as respostas deixaram claro que os discentes gostariam que suas aulas fossem mais contextualizadas e que trouxessem para a sala de aula fatos correlacionados com seu dia a dia.

A aula contextualizada foi uma estratégia que contribuiu para a motivação no processo ensino/aprendizagem. Sabe-se que este processo é complicado e sofre inúmeras mudanças no decorrer tempo, envolve várias variáveis e múltiplos saberes. Por este motivo é que o ensino de química deve ser trabalhado com o intuito de despertar o interesse por temas muitas vezes abstratos e, aparentemente, sem relação com o cotidiano dos alunos, nesta pesquisa a diminuição no desvio padrão indicou que a dispersão das notas foi consideravelmente minimizada, sugerindo que a metodologia teve êxito quanto ao despertar do interesse pelo conteúdo. A contextualização é uma ferramenta essencial para a construção de conceitos no processo de ensino e pode ser bem aplicado no tocante aos tópicos de Equilíbrio Químico, a partir de reações que façam parte do cotidiano dos alunos.

\section{REFERÊNCIAS}

ASTOLFI, J.-P.; DEVELAY, M. A didática das ciências. 16. ed. : Ed. Papirus, 2014.

BEJARANO, N. R. R.; CARVALHO, A. M. P. de. A educação química no brasil através das pesquisas e publicações da área. Educação Química, 2000.

BRASIL. Decreto n 3.276, de 06 de dezembro de 1999. regulamenta no âmbito federal, dispositivos da lei $n$ 9.394 de 20 de dezembro de 1996, que dispõe sobre a formação em nível superior de professores para atuar na educação básica, e dá outras providências. $D O U$ 07/12/1999, Brasília, 1999.

\section{- Parâmetros Curriculares Nacionais para o} Ensino Médio: Ciências da Natureza, Matemática e suas Tecnologias. Brasília: Ministério da Educação Secretaria de Educação Média e Tecnológica, 1999. DOU, 07/12/1999.

CARDOSO, S. P.; COLINVAUX, D. Explorando a motivação para estudar química. Química Nova na Escola, v. 23, n. 3, p. 401-404, 2000. 
CONTEXTUALIZAÇÃO NO ENSINO DO EQUILÍBRIO QUÍMICO: UMA PROPOSTA METODOLÓGICA

CHASSOT, A. Alfabetização Científica: Questões e Desafios Para a Educação. 4. ed. : Unijuí, 1995.

CORREA., S. M. B. B. Probabilidade e Estatística. 2. ed. : PucMinas, 2003.

FELTRE, R. Química. Físico-Química. 6. ed. : Moderna, 2004.

GARRITZ, A.; RAVIOLO, A. Analogias no ensino do equilíbrio químico. Química Nova na Escola, n. 27, p. 13-25, 2008.

GIL, A. C. Como elaborar projeto de pesquisa. 5. ed. : Atlas, 2010.

LEAL, M. C. Didática da química: Fundamentos e práticas para o ensino médio. 1. ed. Belo Horizonte: Ed. Dimensão, 2010.

MALDANER, O. A.; ZANON, L. B. Fundamentos e propostas de ensino de química para a educação básica no Brasil. 1. ed. : Unijuí, 2007.

MOL, G. S. Ensino de química: Visões e reflexões. 1. ed. : Unijuí, 2012.

MOREIRA, M. A.; MASINI, E. F. S. Aprendizagem significativa: A teoria da Aprendizagem de David Ausubel. 2. ed. : Moraes, 2006.

NARCISO JR., J. L.; JORDÃO, M. Química - Projeto Escola e Cidadania para Todos. 1. ed. : Ed. do Brasil, 2005 .

PONTES, A. N. O ensino de química no nível médio: Um olhar a respeito da motivação. In: ENCONTRO NACIONAL DE ENSINO DE QUÍMICA. Belém - PA: , 2008.

REIS, M. Química - Meio ambiente, Cidadania e Tecnologia. 1. ed. : FTD, 2012. v. 2.

SANTOS, A. O.; SILVA, R.; ANDRADE, D.; LIMA, J. Dificuldades e motivações de aprendizagem em química de alunos do ensino médio investigadas em ações do (pibid/ufs/química). Scientia Plena, v. 9, n. 7(b), 2013.

SANTOS, W. L. P. O ensino de química para formar o cidadão: principais características e condições para a sua implantação na escola secundária brasileira. Dissertação (mestrado em Educação) — Faculdade de Educação, Universidade Estadual de Campinas, 1992. 233f.
SCHNETZLER, R. P. Concepções e alertas sobre formação continuada de professores de química. Química Nova na Escola, n. 16, p. 15-20, 2002.

SCHNETZLER, R. P.; ARAGÃO, R. M. R. Importância, sentido e contribuições da pesquisa para o ensino de química. Química Nova na Escola, n. 1, p. $27-31,1995$.

SCHNETZLER, R. P.; SANTOS, W. L. P. Educação em química: Compromisso com a cidadania. 3. ed. : Unijuí, 2003.

SENE, J. J.; CASTILHO, L. N. P.; DINELLI, L. R.; KIILL, K. B. Equilíbrio químico de sais pouco solúveis e o caso celobar. Química Nova na Escola, v. 24, p. 43-45, 2006.

SILVA, R. R. da; FERREIRA, G. A. L.; BAPTISTA, J. de A.; DINIZ, F. V. A química e a conservação dos dentes. Química Nova na Escola, v. 13, p. 3 - 8, 2001.

TAROCO, J. R. A experimentação no Ensino de Química em alguns artigos de Língua Inglesa (MONOGRAFIA). Dissertação (Mestrado) Universidade Federal de São João Del-Rei, 2015.

TURCI, C. C.; SANTOS, P. M. L. dos; SILVA, J. F. M. da; GUERRA, A. C. de O.; JÚNIOR, E. N. D.; SOUZA, G. C. de; FRANCISCO, T. V.; SOUZA, F. R. de; SANTOS, F. L. dos; RODRIGUES, Ú. S. A.; LIMA, M. T.; SILVA, F. C. da; SANTOS, M. A. A. S. Análise de alimentos: Contextualização e interdisciplinaridade em cursos de formação de professores. Química Nova na Escola, v. 38, n. 2, p. 149 - 156, 2016.

VERGARA, S. C. Projetos e relatórios de pesquisa em administração. 3. ed. : Atlas, 2000.

WARTHA, E. J.; SILVA, E. L. da; BEJARANO, N. R. R. Cotidiano e contextualização no ensino de química. Química Nova na Escola, v. 35, n. 2, p. 84 91, 2013. 